\title{
Perfect Storm of Inpatient Communi- cation Needs and an Innovative Solution Utilizing Smartphones and Secured Messaging
}

Neha Patel ${ }^{1}$; James E. Siegler2; Nathaniel Stromberg ${ }^{3}$; Neil Ravitz ${ }^{4}$; C. William Hanson ${ }^{5}$

${ }^{1}$ Perelman School of Medicine, the University of Pennsylvania, Philadelphia, Pennsylvania;

${ }^{2}$ Department of Neurology, Hospital of the University of Pennsylvania, Philadelphia, Pennsylvania;

${ }^{3}$ Center for Clinical Effectiveness \& Quality Improvement, University of Pennsylvania Health System, Philadelphia, Pennsylvania; ${ }^{4}$ Presbyterian Medical Center, Philadelphia, Pennsylvania;

${ }^{5}$ Department of Anesthesia, and Chief Medical Informatics Officer, University of Pennsylvania Health System, Philadelphia, Pennsylvania

\author{
Keywords \\ Communication, provider-provider interaction, mobile, secure texting, secure-messaging
}

\section{Summary}

Background: In hospitals, effective and efficient communication among care providers is critical to the provision of high-quality patient care. Yet, major problems impede communications including the frequent use of interruptive and one-way communication paradigms. This is especially frustrating for frontline providers given the dynamic nature of hospital care teams in an environment that is in constant flux. Methods: We conducted a pre-post evaluation of a commercially available secured messaging mobile application on 4 hospital units at a single institution for over one year. We included care providers on these units: residents, hospitalists, fellows, nurses, social workers, and pharmacists. Utilization metrics and survey responses on clinician perceptions were collected and analyzed using descriptive statistics, the Kruskal-Wallis test, and Mann-Whitney $\mathrm{U}$ test where appropriate.

Results: Between May 2013 and June 2014, 1,021 providers sent a total of 708,456 messages. About $85.5 \%$ of total threads were between two providers and the remaining were group messages. Residents and social workers/clinical resource coordinators were the largest per person users of this communication system, sending 9 (IQR 2-20) and 9 (IQR 2-22) messages per person per day, and receiving 18 (IQR 5-36) and 14 (IQR 5-29) messages per person per day, respectively ( $p=0.0001)$. More than half of the messages received by hospitalists, residents, and nurses were read within a minute. Communicating using secured messaging was found to be statistically significantly less disruptive to workflow by both nursing and physician survey respondents ( $p<0.001$ for each comparison). Conclusions: Routine adoption of secured messaging improved perceived efficiency among providers on 4 hospital units. Our study suggests that a mobile application can improve communication and workflow efficiency among providers in a hospital. New technology has the potential to improve communication among care providers in hospitals.

\section{Correspondence to:}

Neha Patel, MD, MS

3400 Spruce Street

5020 Maloney

Philadelphia, PA 19104

Neha.Patel@uphs.upenn.edu

Fax: 215-662-6250

Phone: 215-847-9916
Appl Clin Inform 2016; 7: 777-789

http://dx.doi.org/10.4338/ACI-2015-11-RA-0151

received: November 14, 2015

accepted: March 27, 2016

published: August 10, 2016

Citation: Patel N, Siegler JE, Stromberg N, Ravitz N, Hanson CW. Perfect storm of inpatient communication needs and an innovative solution utilizing smartphones and secured messaging. Appl Clin Inform 2016; 7: 777-789

http://dx.doi.org/10.4338/ACI-2015-11-RA-0151 


\section{Background}

Today's care of patients in hospitals inevitably involves multiple health care providers who must coordinate and communicate effectively in an environment that is uncertain and in constant flux. These providers spend a substantial amount of time communicating with each other than on other patient activities, such as talking with or examining patients $[1,2]$. Not only is the communication space enormous, but it also plays a substantial role within health care systems. Effective communication among health care providers is critical to providing high-quality care [3-5]. Studies have shown that communication failures are the largest contributor to adverse events and poor outcomes in health care systems [6, 7]. Furthermore, this inefficient communication is estimated to cost U.S. hospitals upwards of $\$ 12$ billion per annum [8].

Yet, hospitals' communication systems still receive much less attention than information systems such as electronic health records. There is now growing literature on the limitations of traditional hospital communication systems such as alpha-numeric pagers, landlines, email, and unit intercoms [8-12]. Health care providers navigate an increasingly fragmented communication space that forces them to communicate through several disparate modes: face-face interactions, phone calls, oneways texts, pagers, or email. This results in frequent interruptions in workflow, inability to indicate the urgency of messages, delays in sending or receiving information, and frustrations among providers from the various communication systems in a health care setting.

To address clinical communication frustrations, a variety of solutions, including the use of instant messaging or smartphone based email or texting have been implemented to replace traditional pagers in diverse health care settings. Smart devices, such as smartphones or tablets, are increasingly adopted by physicians and being used in the clinical setting for internet access, team coordination, and information transmission via email or texting [13]. However, smartphone texting of patient protected health information (PHI) through insecure channels and without adequate safeguards can expose a health care system to potential privacy and security violations that may result in adverse legal and financial consequences. The use of third-party secured-messaging solutions, such as mobile applications that are downloaded on smartphones, is a potential solution safeguard for health care systems [14]. Recently, a smart phone based Health Insurance Portability and Accountability Act (HIPAA)-compliant messaging solution was implemented in an inpatient setting and found to be more efficient than paging [15]. However, overall usage was low and inconsistent among the 49 participants, who did not include nurses. A similar smartphone messaging tool developed by a health care system was perceived to improve efficiency and accountability among both trainees and nurses on general internal medicine units and had high usage among staff [5]. Messaging in this study was centralized around a designated team smartphone that was carried by the primary physician of the team, and nurses utilized the tool via a desktop interface and not smartphones. Despite the positive findings, some earlier studies suggested that a mobile messaging system might create unwelcome interruptions during patient interviews or other provider routines leading to poor adoption among various providers $[10,16]$.

\section{Objectives}

We hypothesize that compared to commonly used tools to communicate, such as pagers, landlines, or phone calls; a unified communication system of texting between all hospital providers in a care team has the potential to be an efficient and effective means for communicating information contributing to better patient care coordination. Our objective was to determine if a commercially available smartphone based secured messaging application has the potential to allow providers to communicate efficiently and effectively as a care team. To the best of our knowledge, ours is the first study that evaluates utilization and perception of using a smartphone based HIPAA-complaint messaging application among various health care providers in a teaching hospital. 


\section{Methods}

\subsection{Setting and Participants}

This was a pre-post study. The study was conducted on 1 surgical unit and 3 general medical units at the Hospital of University of Pennsylvania, a tertiary-care academic teaching center affiliated with the University of Pennsylvania Health System. The surgical 24-bed unit consisted of clinical teams staffed by vascular attendings and fellows, surgical residents, and advanced practitioners. One of the three 40-bed medical units was staffed primarily by hospitalists and the remaining general medical units consisted of clinical teams staffed primarily by hospitalists, advanced practitioners (APs), and internal medicine residents. Additionally, residents from emergency medicine and psychiatry rotate on these units during their general medical service blocks. Each unit is also staffed by registered nurses, clinical pharmacists, social workers (SW), secretaries, and clinical resource coordinators (CRCs). All units are characterized by a high volume of medically and surgically complex patients and a high turnover of physicians. Generally the clinicians on these units do not have geographically based patient assignments.

Prior to our intervention, non-face-to-face, non-urgent communication with attendings, residents, or APs was managed with a "one-way," web-browser-to-pager texting system. Using this system, nurses, pharmacists, SWs, secretaries, and CRCs were able to send one-way alpha-numeric text messages to physicians and APs. Additionally, residents, SWs, CRCs, APs, and pharmacists also called each other or nurses using individual hospital-issued cell phones (which were, in most instances, not smartphones). Non face-to-face communication with nurses or secretaries was handled using each unit's landline or intercom system.

\subsection{Intervention}

We worked with the Penn Medicine Center for Health Care Innovation to gain insight into various providers' workflow and their frustrations with communicating with other providers. Our goal was to select desired functionalities of a communication tool based on our providers' daily communication needs such as alphanumeric character messaging, picture messaging, voice messaging, individual or group messaging with the ability to remove or add individual providers within a message thread, read receipts, personalized ring tone for messages received, and status updates regarding work availability (e.g. "off duty" vs. "on duty" vs. "busy"). Ultimately we chose a mobile application vendor, Cureatr, which is a commercially available, HIPAA-complaint messaging application for Android and iOS platforms utilized for transmission of encrypted text messages via hospital wireless fidelity (Wi-Fi) network or commercial cellular networks. Currently there are numerous similar mobile applications which range from basic secure messaging to more robust functionality and interface capabilities, such as directory or scheduling information.

Beginning May 6, 2013, select care providers on the study units, which included nurses, pharmacists, SWs, secretaries, CRCs, residents, fellows, and attendings were instructed to utilize the Cureatr application for non-urgent communication, such as medication adjustments, clarifications of plan of care, and discharge planning using the Cureatr application. Urgent information, such as clinical deterioration or high-risk medication changes, would still be communicated by calling the provider. Care providers such as consultants, bed managers, ancillary service staff, and providers from units other than the 4 units in our study were excluded from the study. The project's clinical champions meet with leadership of the included care providers and worked with them to communicate the new tool that would be implemented for communication. A participation rate could not be calculated since it was not possible to calculate who was not using the tool to communicate.

Participants, except for unit secretaries, were provided devices iPhones or iTouches or allowed to use their own personal devices. Thirteen iTouches were used by nurses on one unit and the remaining units were provided iPhones (a total of 96 iPhones). Given their limited need for mobility, unit secretaries accessed Cureatr from hospital desktop computers through a web application. Each participant created unique password-protected Cureatr accounts. Messages were sent between providers by typing in the name(s) of the desired receiver of the message and filling in the patient name, room number, and subject heading and text field of a message template. Training on the usage of the 
application was demonstrated by the project's clinical champions on as needed basis during the first two days of implementation. Communication emails and an internal website provided frequently asked questions and tutorials to providers. This work was formally approved by the University of Pennsylvania Institutional Review Board and waived the requirement for consent.

\subsection{Usage}

Messages using Cureatr from May 6, 2013 to June 30, 2014 were analyzed to evaluate utilization, pattern, and adoption of the communication solution. Administrators, such as the project leaders or information technology staff, and medical student usages were excluded from the analysis given that they were not primary patient care providers. The extracted message information included usage by provider role, number of threads and messages sent to an individual provider or group of providers, character length of messages, and time-to-read statistics. "Thread" refers to a collection of message(s) shared among providers with a unique subject header (e.g. "Jane Doe, room 1271"), whereas thread length describes the number of unique messages within a given thread. Character length refers to the number of alphanumeric characters, excluding spaces, in a given message. Extreme participants (termed "hyper-users" and "hypo-users") were recognized if they contributed more messages than $95 \%$ of all users, or less than $5 \%$ of all users, respectively.

\subsection{Surveys}

Pre-intervention surveys were administered to nurses and physicians 2 months prior to implementation (10 items and 9 items, respectively). These surveys assessed attitudes to evaluate perceived measures of efficiency, workflow, and overall satisfaction toward the daily communication practice. Survey items were compiled by reviewing literature for surveys regarding communication practices [17]. Pilot testing of the survey was carried out with 8 nurses, 10 residents (surgical and medical), and 4 hospitalists, and modified based on feedback as performed in similar investigations. Post-intervention surveys (14 items), administered two months after implementation, included each of the baseline survey questions, modified in order to fit the post-intervention change, as well as questions regarding perceived time saved and value of using Cureatr to communicate. Given that select providers such as social workers and nurses did not rotate off the units but did have a high turnover rate and some providers such as residents frequently rotated through the units, we surveyed providers 2 months post implementation to better assess the immediate perceived change using the new communication system.

\subsection{Statistical Analysis}

Numbers of messages per provider (and messages per provider per day) are reported as medians with interquartile range (IQR). Message lengths are reported as medians with IQR. Usage data was compared using descriptive statistics and the Kruskal-Wallis test, where appropriate. Survey responses for select items were reported as median scores on a Likert scale, valued from 1 to 5 (1=strongly disagree, $3=$ neutral response, $5=$ strongly agree), with IQR and compared using the Mann-Whitney U test. STATA version 14.0 (College Station, TX, USA) was used for all analyses. P-values $<0.05$ were considered statistically significant.

\section{Results}

\subsection{Usage Analysis}

A total of 708,456 messages were sent during the 13-month study period. This translated to 130,073 threads on specific patients. Messages between 2 providers constituted $85.4 \%(n=111,039)$ of total threads, while $14.6 \%(\mathrm{n}=19,034)$ were group messages. Only 548 messages contained image attachments $(0.08 \%)$. Usage of the secured messaging application by provider role is shown in Table 1 . Nurses and residents represented the largest contributors of message senders, $43.4 \%(n=307,137)$ vs $32.0 \%(n=226,854)$, and receivers, $35.9 \%(n=366,705)$ vs $39.2 \%(n=399,395)$, respectively, during the 
study period. On average, each SW/CRC sent the most messages (per person) throughout the study period (median 510 messages, IQR 195-4028), followed by nursing staff (median 450, IQR 62-1202), whereas the fewest messages were sent by a given resident (145, IQR 21-538), attending (133, IQR 9-765), and pharmacist (112, 6-354; $\mathrm{p}=0.0001$ by Kruskal-Wallis test). Among group threads, most messages were sent by residents (29.7\%), followed by nurses $(24.9 \% \%)$ and SW/CRCs $(21.4 \%)$.

At the individual level, the median number of messages sent per participant was 474 (IQR 238-674). More messages were sent per provider per day by pharmacists, residents, and SW/CRC than other providers, while more messages were received per provider per day among residents, advanced practitioners and attending physicians ( $\mathrm{p}=0.0001$ for both comparisons, $>$ Table 1$)$. Fortyseven "Hyper-users" contributed 145,111 messages (20.5\%), while 47 "hypo-users" contributed 49 messages total $(0.007 \%)$. The majority of "hyper-users" were nurses $(n=21)$ followed by residents $(n=14)$, while "hypo-users" were more often residents $(n=22)$ than nurses $(n=13)$ or other providers.

- Figure 1a illustrates the total number of messages sent by provider role throughout the study period. The majority of nurses' messages were sent to residents $(59.5 \%, \mathrm{n}=182,822)$, while the majority of residents' messages were sent to nurses $(52.7 \%, n=119,661)$. $>$ Figure $1 b$ illustrates the number of messages sent per sender per day according to provider role. Among individual users, the highest volume of messages were sent from secretaries to nurses (15 messages/secretary/day), followed by resident messages to nurses ( 8 messages/resident/day) and pharmacist messages to residents ( 8 messages/pharmacist/day).

When analyzing the messages sent between nurses and residents, we found that $67.7 \%$ of their conversations contained between 3 and 10 messages, whereas $18.6 \%$ of their conversations could be classified as 'quick replies' since they contained 2 messages. Figure 2 examines the number of characters in each message sent, we found that there was a trend towards shorter messages sent by attendings and residents (median character length, excluding spaces, of 28 [IQR 12-55] and 27 [IQR 12-53], respectively). Longer messages were sent by SWs and CRCs, and pharmacists (median character length 41 [IQR 18-83] and 45 [IQR 19-87], respectively; $<<0.001$ by Kruskal-Wallis test).

Time-to-read statistics were fairly similar across providers with the exception of secretaries, who were found to have to have a longer delay in reading messages sent to them compared to other provider roles as shown in $>$ Figure 3. More than half of messages received by attendings, residents, and nurses were read within 1 minute.

\subsection{Survey results}

Pre-intervention survey data were collected from 136 nurses and 93 physicians, (response rate 69\% and $85 \%$, respectively), whereas post-intervention surveys were collected from 127 nurses and 83 physicians (response rate $64 \%$ and $76 \%$, respectively) as shown in $>$ Table 2 and $>$ Figure 4 . For all items, median responses on perceived efficiency, workflow, and satisfaction with communication were significantly different between pre and post intervention for both nurses and physicians. For example, nursing reported statistically significantly less disruption in their workflow from after using secured messaging and that physicians were more responsive when using secured messaging. Physicians also reported statistically significantly less disruption in their workflow after using secured messaging and reported receiving complete patient information over texts.

\section{Discussion}

In the present study, we describe the implementation and adoption of a mobile secured messaging application to facilitate communication among providers in a hospital. Given that smartphones are now ubiquitous and that texting is a common method of communicating in the general population, we found widespread adoption and sustainment of this communication method among diverse providers in our hospital. The value in utilizing this mobile tool to communicate in health care systems lies in its ease of use and minimal training requirements, as well as the readily availability of similar commercial, HIPAA-compliant third-party messaging applications.

Unlike prior studies, we included primary providers who comprise the hospital care team, such as bedside nurses, SWs, and pharmacists. This allowed us to gain valuable insight on the pattern of interprovider communication. Nurses and residents were the largest contributors of sending and receiving 
messages. This is to be expected given that our institution is a teaching hospital and they are frontline care providers. Among providers at the individual level, we observed a high daily volume of messages from pharmacists to residents ( $3^{\text {rd }}$ highest volume per provider role per day) and from SW/CRC to residents ( $5^{\text {th }}$ highest volume per provider role per day). Although, SW/CRCs sent the most messages per provider, whereas pharmacists and residents sent the most messages per provider per day, this apparent disparity is explained by the fact that SW/CRCs remained on service throughout the study period whereas residents and pharmacists were more likely to rotate off the study units. Therefore, total messages sent per provider could be conceivably lower among providers, such as residents, with less service time whereas these providers could send more messages per day of utilizing the Cureatr application. We also found an overwhelmingly large number of group messages (one in six messages), revealing that our intervention facilitated more virtual team conversations among providers. Permitting this type of any time, any place team communication, enables care team providers to operate under a shared-mental model, a required characteristic of high-functioning teams, and potentially facilitate all care providers knowing a patient's care plan [18]. For example, our participants frequently described that group messaging usually focused on coordinating discharges or addressing a patient's request or concern and facilitated expedited decision making by allowing succinct and quick dialogue. Additionally, unlike the pager which is oneway communication, the bidirectional communication of messaging permitted our providers to reply $d i-$ rectly to each other in order to quickly and effectively respond to inquiries or notifications. We found that many messages were short (fewer than 50 characters), likely representing simple questions or notifications. Combined with the knowledge that the majority of threads involved 3-10 total messages and were typically read in $<1$ minute, we speculate that the most frequent types of inter-provider communication are concise, require minimal discussion or debate, and are rapidly acknowledged. In fact, this best explains why a large proportion of our physicians surveyed reported saving significant time.

Recent literature has identified interruptions in provider workflow to not only be disruptive but to have cognitive implications that can negatively impact patient quality of care.[19] Residents and nurses in our study reported texting on their smart devices was more efficient and less disruptive than using phone calls or pagers. These findings are different from other studies which found using smartphones in hospitals facilitated more interruptions during clinical rounds or other provider routines and worsened interprofessional relationships $[10,17,20]$. We explain Our results highlight that messages sent through texting were non-urgent so could be deferred to later review and did not create significant disruption to workflow requiring interrupting a task to either read or response to the message. This was confirmed in the variation in our time-to-read statistics which showed that our participants did not read all of their messages immediately (i.e. in less than a minute). Our time to read variation supported both nurses' and residents' perceptions that using a secured messaging application was less disruptive while performing clinical duties and allowed them to prioritize patient care tasks effectively. Of note, time-to-respond to message statistics was not reported since responses to the messages could occur in multiple modes depending on the content of the message: call back, face to face interaction, message back, or no response needed. Our study was limited in that we did not analyze the content of the messages and were unable to confirm that the messages sent were non-urgent or urgent in context or about patient care and not personal. This limitation has a possible confounding effect on the interpretation our results. Analyzing the content of the messages to confirm our findings is an area of active research interest at our institution. Second, we did not measure the impact of this intervention on patient outcomes. Since clinical communication is focused on patients, efforts to evaluate how these communication tools impact our patients are necessary. It would be also be helpful to know our patient's perception of their providers using smart devices in the clinical setting. Third we were limited on the effect of the intervention on the number of phone calls, intercom usage, or numeric pages or texts our providers received outside of the Cureatr application. We did not replace our residents', social workers', or CRCs' hospital issued cell phones but instead supplemented them with smartphones and the secured messaging application. This was because we did not include all health care providers, such as consultants, hospital operators, or bed managers, in our study and they could not utilize the secured messaging application to communicate with our study participants. There were reported issues with connectivity while using the tool among the iTtouch users. However, there was no prolonged interruption of texting. Additionally, this was a pre-post study and so it is possible that our participants' perceived improvement in communication would have occurred anyway without the intervention. However, it is unlikely that the perceived improvement of communication was not directly related to the intervention. Finally, our 
study was limited by its single-center design with the use of selected hospital units which may make our results less generalizable to other units in our hospital or other health care systems.

Of note, technical challenges during our study commonly included delayed receipt of messages. This was oftentimes attributed to Wi-fi issues and commonly arose on the unit that used iTouches. However, there was never a prolonged interruption of utilizing the secured messaging application among our providers during the study period.

Costs of implementation included data plans for the 96 iPhones (\$70/month per device), 13 iTouches ( $\$ 200$ per device), and accessories ( $\$ 25-\$ 40$ per device). The Chief Medical Information Officer provided funding to support this study. Future work on the tangible benefit rather than perceived improved efficiency is underway to support a hospital funded expansion of secured messaging at our institution.

\section{Conclusion}

Despite these limitations, we feel our data are compelling and should encourage hospitals to adopt similar secured mobile communication systems. The rising use of smartphones and mobile applications in everyday life, led to the rapid adoption and long term sustainability of this innovative solution to the communication conundrum in our hospital [21]. Despite minimal training resources deployed in our study, we observed long term sustainability, implying that this communication tool was similar to most everyday mobile applications: easy to learn and use. The dynamic environment of hospital units combined with the paucity of a geographically based patient assignment for many providers call for solutions such as this to optimize the efficacy of mobile inter-provider communication. These solutions have the potential to support a team-based culture of care if messages can be forwarded or copied to another provider, patient-centric messages could be saved in the EHR, or integration of order entry to manage routine tasks associated with texts [22].

Both operational efficiencies in the health care system and patient care outcomes are intimately dependent on effective and efficient communication among care providers. Additionally, improved efficiency of communication allows health care providers more time for patient-provider interaction and reduces unnecessary frustration among providers. For other hospitals to consider adopting a similar solution, considerations on identifying the appropriate third-party messaging application to meet their providers communication needs and setting policies on device procurement (i.e. allow staff to use their personal device or provide a device) would be first steps.

In summary, we implemented a commercial HIPAA secured messaging application and found it to be highly utilized, well-received among providers, and sustainable for more than a year in a fast-paced and dynamic clinical environment. The findings of this study warrant validation on a larger scale and impact on patient outcomes to confirm the effectiveness and safety of mobile secured-messaging solutions.

\section{Clinical Relevance Statement}

A positive approach to mobile health in health care requires blending surveillance of new technologies-looking for those that add value when introduced in clinical practice amidst a sea of those that will not. This manuscript describes the implementation and effect of utilizing a secured messaging mobile application at our academic healthcare system. We have found that this communication tool has changed the way our care providers communicate in the hospital.

\section{Conflict of Interest}

The authors report no competing financial interests exist, including financial compensation from Cureatr for the use of its system. The views and opinions expressed herein do not reflect those of Cureatr or its affiliates, and no Cureatr official has contributed to the conceptualization or content of this manuscript. The authors report no conflict of interests in the research.

\section{Human Subjects Protections}

Human subjects were included in this study. This work was formally approved by the University of Pennsylvania Institutional Review Board. Acknowledgements: The support from the Office of CMO and Nursing Leadership. 


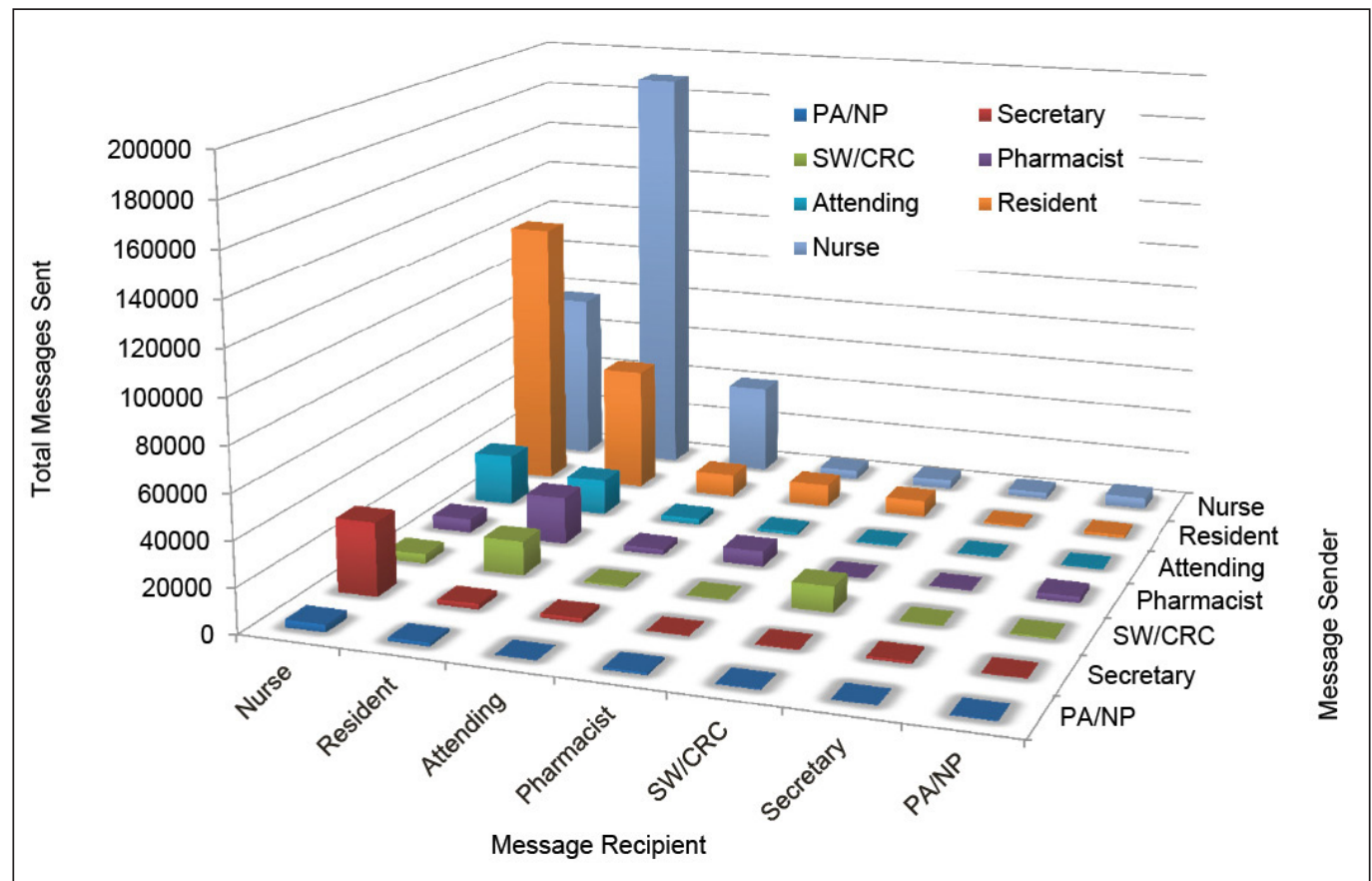

Fig. 1a Number of messages sent by provider role. Graphical representation whereby the vertical axis represents number of messages sent during study period, the $\mathrm{x}$-axis represents the message recipient, and the z-axis represents the message sender. SW denotes social worker, CRC clinical resource coordinator. AP denotes advanced practitioner.

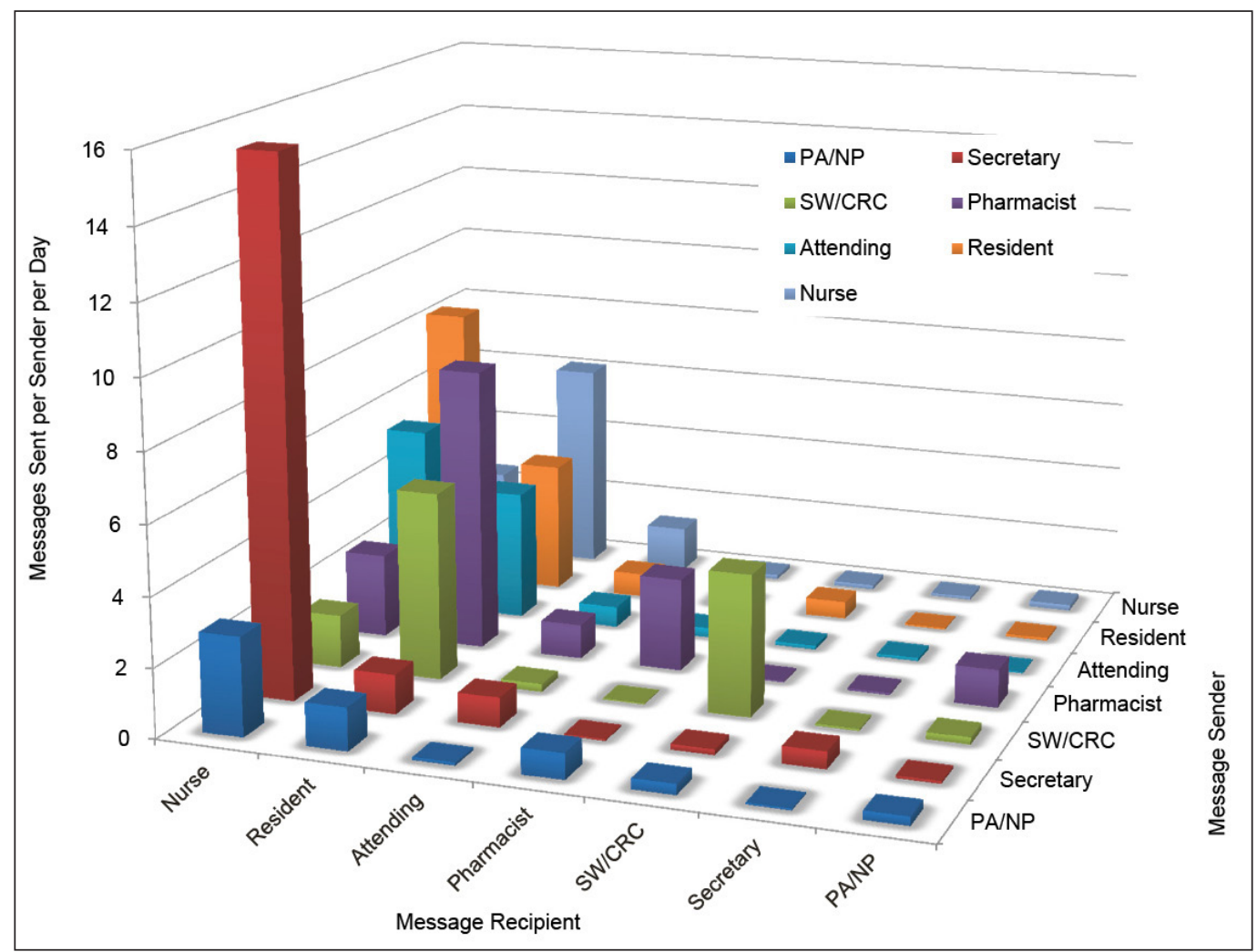

Fig. 1b Number of messages received by provider role. Graphical representation whereby the vertical axis represents number of messages sent during study period, the $x$-axis represents the message recipient, and the $z$-axis represents the message sender. SW denotes social worker, CRC clinical resource coordinator. AP denotes advanced practitioner.

C Schattauer $2016 \quad$ Neha Patel et al.: Utilizing Smartphones and a Secured Messaging Application for Hospital Communication 

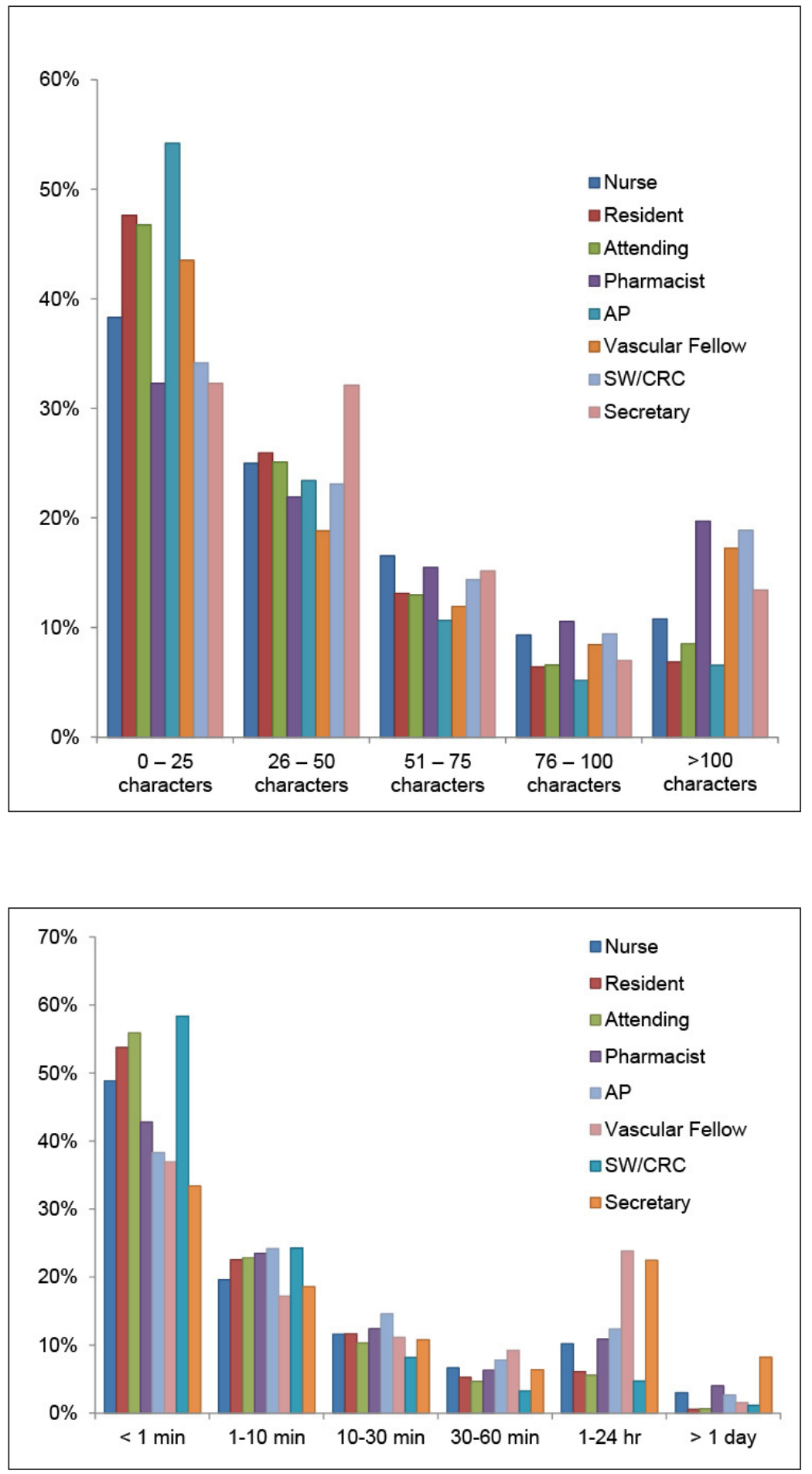

Fig. 2

Character length of messages sent by provider role. Y-axis reflects the percentage of messages sent by a given provider role, and $x$-axis reflects the character length per message. For example, $47 \%$ of all messages sent by attendings had lengths of 0-25 characters, while $32 \%$ of all messages sent by unit secretaries had lengths of $0-25$ characters. SW/CRC denotes social worker/clinical resource coordinator. AP denotes advanced practitioner.

Fig. 3

Average time-to-read message per provider. SW/CRC denotes social worker/clinical resource coordinator. AP denotes advanced practitioner. 


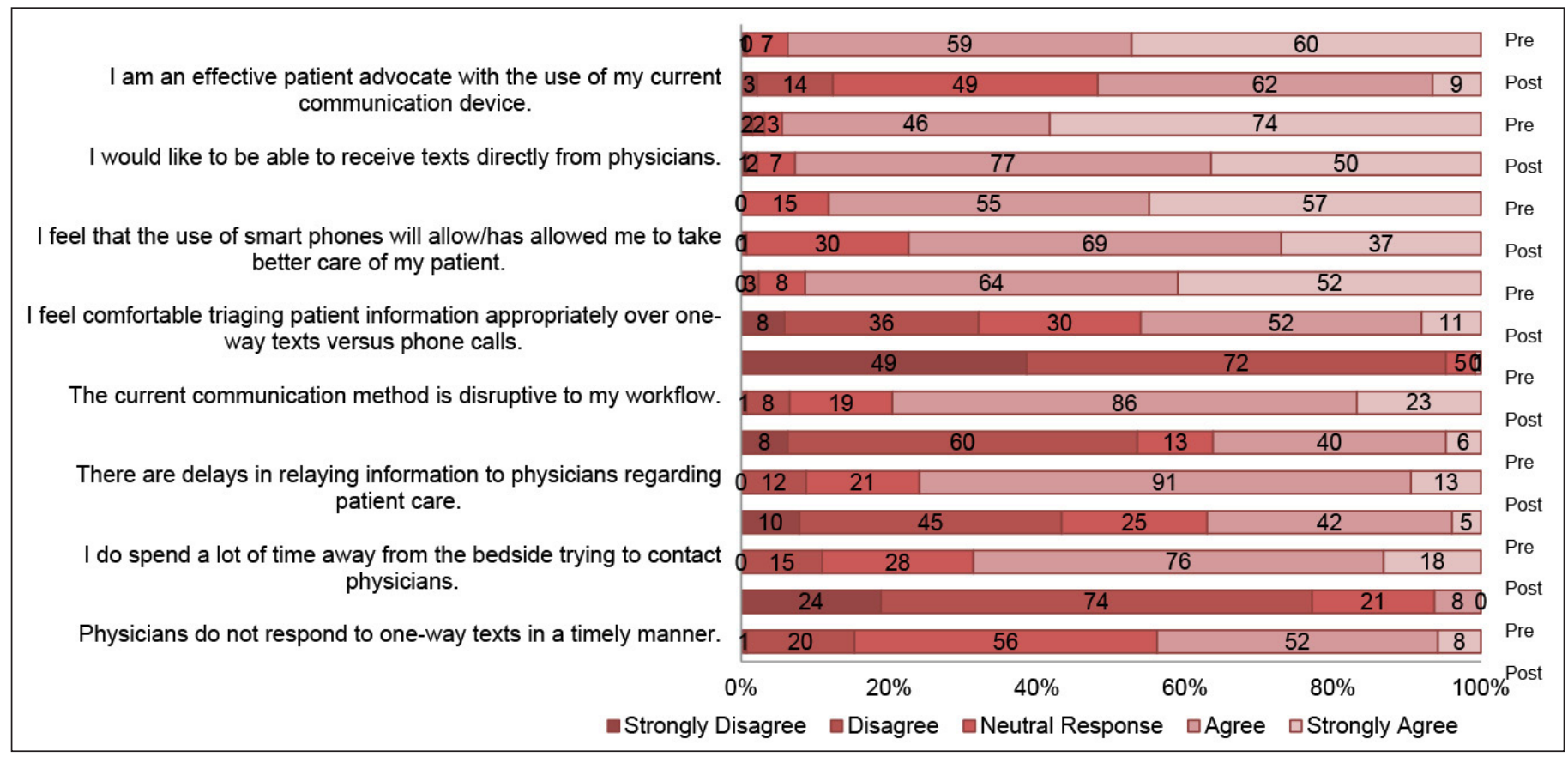

Fig. 4a Provider pre and post assessment on communication satisfaction

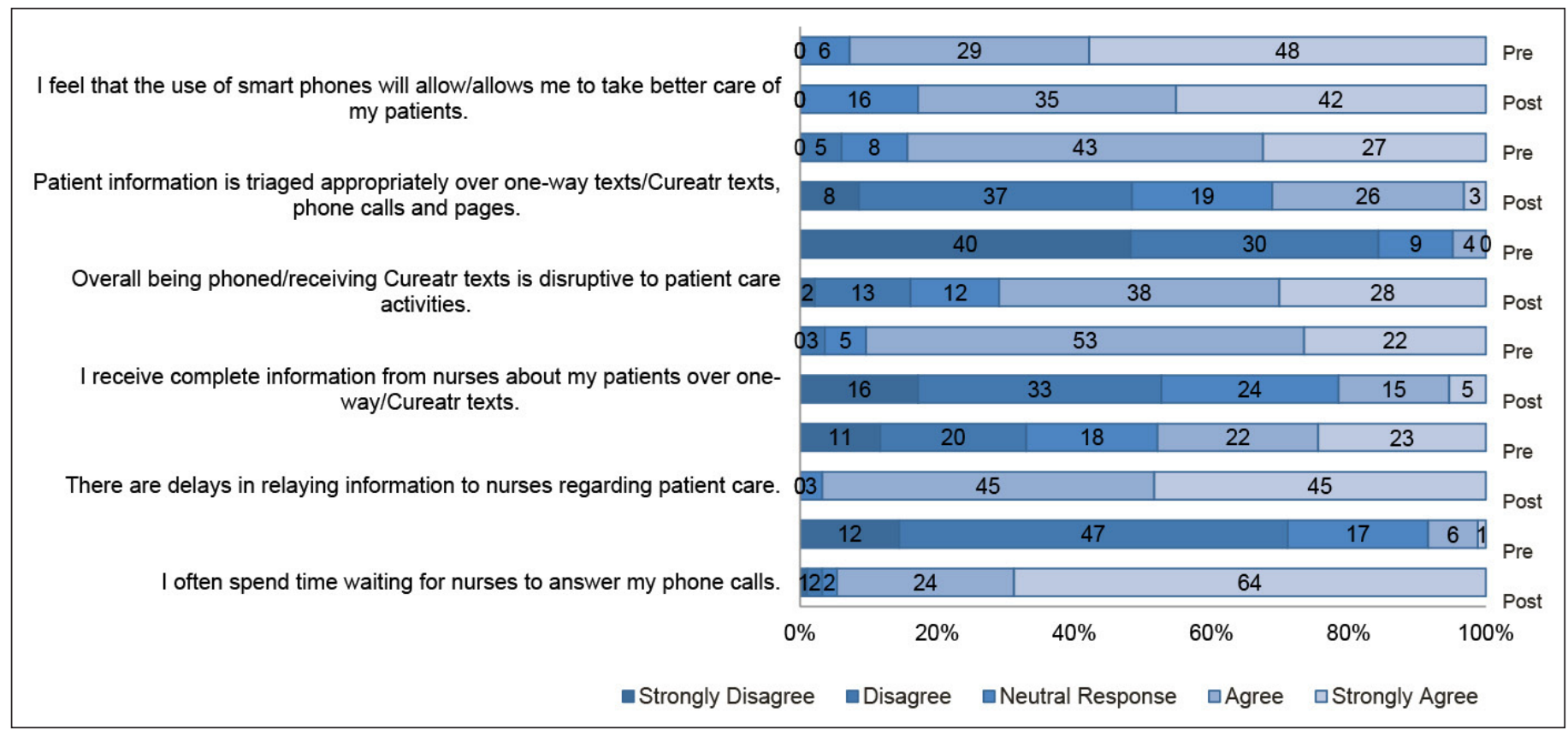

Fig. 4b Nursing pre and post assessment on communication satisfaction 
Table 1 Usage of the secured messaging application by provider role

\begin{tabular}{|c|c|c|c|c|c|c|c|c|}
\hline $\begin{array}{l}\text { Provider } \\
\text { Role }\end{array}$ & $\begin{array}{l}\text { Days } \\
\text { of } \\
\text { Study } \\
\text { Partici- } \\
\text { pation }\end{array}$ & $\begin{array}{l}\text { Mean } \\
\text { Total } \\
\text { Users } \\
\text { Per } \\
\text { Day }\end{array}$ & $\begin{array}{l}\text { Sent } \\
\text { Count }\end{array}$ & $\begin{array}{l}\text { Receiv- } \\
\text { ed } \\
\text { Count }\end{array}$ & $\begin{array}{l}\text { Mean } \\
\text { Senders } \\
\text { Per Day }\end{array}$ & $\begin{array}{l}\text { Mean } \\
\text { Recipi- } \\
\text { ents } \\
\text { Per Day }\end{array}$ & $\begin{array}{l}\text { Median No. } \\
\text { Messages } \\
\text { Sent per } \\
\text { Sender per } \\
\text { Day (IQR)* }\end{array}$ & $\begin{array}{l}\text { Median No. } \\
\text { Messages Re- } \\
\text { ceived per } \\
\text { Recipient per } \\
\text { Day (IQR)* }\end{array}$ \\
\hline Nurse & 426 & 84.57 & 307,137 & 366,705 & 72.58 & 80.52 & $5(2-12)$ & $6(2-13)$ \\
\hline Resident & 425 & 38.63 & 226,854 & 399,995 & 34.50 & 37.61 & $9(2-20)$ & $18(5-36)$ \\
\hline PA/NP & 424 & 4.55 & 13,503 & 48,931 & 2.87 & 4.52 & $2(0-10)$ & $16(6-35)$ \\
\hline Attending & 425 & 10.51 & 42,312 & 77,857 & 9.97 & 10.21 & $8(3-14)$ & $15(6-25)$ \\
\hline Pharmacist & 421 & 6.60 & 43,063 & 35,446 & 6.14 & 6.25 & $11(3-23)$ & $8(3-17)$ \\
\hline Secretary & 414 & 5.71 & 25,296 & 12,115 & 5.15 & 4.68 & $5(2-12)$ & $3(1-6)$ \\
\hline SW / CRC & 421 & 7.65 & 46,184 & 67,666 & 6.64 & 7.44 & $9(2-22)$ & $14(5-29)$ \\
\hline
\end{tabular}

IQR denotes interquartile range, PA physician assistant, NP nurse practitioner, SW social worker, and CRC clinical resource coordinator.

${ }^{*} \mathrm{p}=0.0001$ by Kruskal-Wallis test.

Table 2 Nurses' and Providers' perceptions on communication pre-post the secured messaging intervention

\begin{tabular}{|c|c|c|c|c|c|}
\hline $\begin{array}{l}\text { Statement } \\
\text { Measure }\end{array}$ & $\begin{array}{l}\text { Pre-Intervention } \\
\text { Statement }\end{array}$ & $\begin{array}{l}\text { Pre-Interven- } \\
\text { tion Response, } \\
\text { Median (IQR) }\end{array}$ & $\begin{array}{l}\text { Post-Interven- } \\
\text { tion Statement }\end{array}$ & $\begin{array}{l}\text { Post-Interven- } \\
\text { tion Response, } \\
\text { Median (IQR) }\end{array}$ & P-value \\
\hline & NURSES $(n=136)$ & & NURSES $(n=127)$ & & \\
\hline Efficient & $\begin{array}{l}\text { Physicians do not re- } \\
\text { spond to one-way texts } \\
\text { in a timely manner. }\end{array}$ & $3(3-4)$ & $\begin{array}{l}\text { Physicians do not } \\
\text { respond to Cureatr } \\
\text { in a timely manner. }\end{array}$ & $2(2-2)$ & $<0.0001$ \\
\hline Efficient & $\begin{array}{l}\text { I do spend a lot of time } \\
\text { away from the bedside } \\
\text { trying to contact phys- } \\
\text { icians. }\end{array}$ & $4(3-4)$ & $\begin{array}{l}\text { I do spend a lot of } \\
\text { time away from the } \\
\text { bedside trying to } \\
\text { contact physicians. }\end{array}$ & $3(2-4)$ & $<0.0001$ \\
\hline Efficient & $\begin{array}{l}\text { There are delays in re- } \\
\text { laying information to } \\
\text { physicians regarding } \\
\text { patient care. }\end{array}$ & $4(4-4)$ & $\begin{array}{l}\text { There are delays in } \\
\text { relaying information } \\
\text { to physicians re- } \\
\text { garding patient } \\
\text { care. }\end{array}$ & $2(2-4)$ & $<0.0001$ \\
\hline Workflow & $\begin{array}{l}\text { The current communi- } \\
\text { cation method, receiv- } \\
\text { ing phone calls, is dis- } \\
\text { ruptive to my workflow. }\end{array}$ & $4(4-4)$ & $\begin{array}{l}\text { Receiving Cureatr } \\
\text { texts is disruptive to } \\
\text { my workflow. }\end{array}$ & $2(1-2)$ & $<0.0001$ \\
\hline Satisfaction & $\begin{array}{l}\text { I feel comfortable triag- } \\
\text { ing patient information } \\
\text { appropriately over one- } \\
\text { way texts versus phone } \\
\text { calls. }\end{array}$ & $3(2-4)$ & $\begin{array}{l}\text { I feel comfortable } \\
\text { triaging patient in- } \\
\text { formation appropri- } \\
\text { ately over Cureatr } \\
\text { texts versus phone } \\
\text { calls. }\end{array}$ & $4(4-5)$ & $<0.0001$ \\
\hline Satisfaction & $\begin{array}{l}\text { I feel that the use of } \\
\text { smart phones will allow } \\
\text { me to take better care } \\
\text { of my patients. }\end{array}$ & $4(4-5)$ & $\begin{array}{l}\text { I feel that the use of } \\
\text { smart phones will } \\
\text { allow me to take } \\
\text { better care of my } \\
\text { patients. }\end{array}$ & $4(4-5)$ & 0.0009 * \\
\hline
\end{tabular}


Table 2 Continued

\begin{tabular}{|c|c|c|c|c|c|}
\hline $\begin{array}{l}\text { Statement } \\
\text { Measure }\end{array}$ & $\begin{array}{l}\text { Pre-Intervention } \\
\text { Statement }\end{array}$ & $\begin{array}{l}\text { Pre-Interven- } \\
\text { tion Response, } \\
\text { Median (IQR) }\end{array}$ & $\begin{array}{l}\text { Post-Interven- } \\
\text { tion Statement }\end{array}$ & $\begin{array}{l}\text { Post-Interven- } \\
\text { tion Response, } \\
\text { Median (IQR) }\end{array}$ & P-value \\
\hline Satisfaction & $\begin{array}{l}\text { I would like to be able } \\
\text { to receive texts directly } \\
\text { from physicians. }\end{array}$ & $4(4-5)$ & $\begin{array}{l}\text { I like being able to } \\
\text { receive Cureatr } \\
\text { texts directly from } \\
\text { other providers } \\
\text { (physicians, nurses, } \\
\text { CRC, social workers } \\
\text { or pharmacists). }\end{array}$ & $5(4-5)$ & 0.0008 \\
\hline \multirow[t]{2}{*}{ Satisfaction } & $\begin{array}{l}\text { I am an effective pa- } \\
\text { tient advocate with the } \\
\text { use of my current com- } \\
\text { munication device. }\end{array}$ & $4(3-4)$ & $\begin{array}{l}\text { I am an effective } \\
\text { patient advocate } \\
\text { with the use of Cu- } \\
\text { reatr. }\end{array}$ & $4(4-5)$ & $<0.0001$ \\
\hline & PHYSICIANS $(n=93)$ & & $\begin{array}{l}\text { PHYSICIANS } \\
(n=83)\end{array}$ & & \\
\hline Efficient & $\begin{array}{l}\text { I often spend time wait- } \\
\text { ing for nurses to answer } \\
\text { my phone calls. }\end{array}$ & $4(4-5)$ & $\begin{array}{l}\text { I often spend time } \\
\text { waiting for nurses } \\
\text { to answer my Cu- } \\
\text { reatr texts. }\end{array}$ & $2(2-3)$ & $<0.0001$ \\
\hline Efficient & $\begin{array}{l}\text { There are delays in re- } \\
\text { laying information to } \\
\text { nurses regarding pa- } \\
\text { tient care. }\end{array}$ & $4(4-5)$ & $\begin{array}{l}\text { There are delays in } \\
\text { relaying information } \\
\text { to nurses regarding } \\
\text { patient care. }\end{array}$ & $3(2-4)$ & $<0.0001$ \\
\hline Workflow & $\begin{array}{l}\text { I receive complete infor- } \\
\text { mation from nurses } \\
\text { about my patients over } \\
\text { one-way texts. }\end{array}$ & $2(2-3)$ & $\begin{array}{l}\text { I receive complete } \\
\text { information from } \\
\text { nurses about my } \\
\text { patients over Cu- } \\
\text { reatr texts. }\end{array}$ & $4(4-5)$ & $<0.0001$ \\
\hline Workflow & $\begin{array}{l}\text { Overall being phoned is } \\
\text { disruptive to patient } \\
\text { care activities. }\end{array}$ & $4(3-5)$ & $\begin{array}{l}\text { Receiving Cureatr } \\
\text { texts is disruptive to } \\
\text { my workflow. }\end{array}$ & $2(1-2)$ & $<0.0001$ \\
\hline Satisfaction & $\begin{array}{l}\text { Patient information is } \\
\text { triaged appropriately } \\
\text { over one-way texts, } \\
\text { phone calls and pages. }\end{array}$ & $3(2-4)$ & $\begin{array}{l}\text { Patient information } \\
\text { is triaged appropri- } \\
\text { ately over Cureatr } \\
\text { texts and phone } \\
\text { calls. }\end{array}$ & $4(4-5)$ & $<0.0001$ \\
\hline Satisfaction & $\begin{array}{l}\text { I feel that the use of } \\
\text { smart phones will allow } \\
\text { me to take better care } \\
\text { of my patients. }\end{array}$ & $4(4-5)$ & $\begin{array}{l}\text { I feel that the use of } \\
\text { smart phones } \\
\text { allows me to take } \\
\text { better care of my } \\
\text { patients. }\end{array}$ & $5(4-5)$ & 0.0433 \\
\hline
\end{tabular}

Due to anonymity of survey respondents, it is unclear which respondents overlapped in the pre- and post-intervention periods. Groups were compared using the Mann-Whitney $\mathrm{U}$ test. IQR denote interquartile range.

* This comparison favors the post-intervention response (more providers answered positively toward the post-intervention statement). 


\section{References}

1. Block L, Habicht R, Wu AW, Desai SV, Wang K, Silva KN, Niessen T, Oliver N, Feldman L. In the wake of the 2003 and 2011 duty hours regulations, how do internal medicine interns spend their time? J Gen Intern Med 2013; 28: 1042-1047.

2. Hendrich A, Chow MP, Skierczynski BA, Lu Z. A 36-hospital time and motion study: How do medicalsurgical nurses spend their time? Perm J 2008; 12: 25-34.

3. Parker J, Coiera E. Improving clinical communication: A view from psychology. J Am Med Inform Assoc 2000; 7: 453-461.

4. Wu RC, Tzanetos K, Morra D, Quan S, Lo V, Wong BM. Educational impact of using smartphones for clinical communication on general medicine: More global, less local. J Hosp Med 2013; 8: 365-372.

5. Wu R, Lo V, Morra D, Appel E, Arany T, Curiale B, Ryan J, Quan S. A smartphone-enabled communication system to improve hospital communication: Usage and perceptions of medical trainees and nurses on general internal medicine wards. J Hosp Med 2015; 10: 83-89.

6. McElroy LM, Ladner DP, Holl JL. The role of technology in clinician-to-clinician communication. BMJ Qual Saf 2013; 22: 981-983.

7. Coiera E. When conversation is better than computation. J Am Med Inform Assoc 2000; 7: 277-286.

8. Agarwal R, Sands DZ, Schneider JD. Quantifying the economic impact of communication inefficiencies in u.S. Hospitals. J Healthc Manag 2010; 55: 265-281.

9. Coiera E, Tombs V. Communication behaviours in a hospital setting: An observational study. BMJ 1998; 316: 673-676.

10. Quan SD, Wu RC, Rossos PG, Arany T, Groe S, Morra D, Wong BM, Cavalcanti R, Coke W, Lau FY. It's not about pager replacement: An in-depth look at the interprofessional nature of communication in healthcare. J Hosp Med 2013; 8: 137-143.

11.Patel SP, Lee JS, Ranney DN, Al-Holou SN, Frost CM, Harris ME, Lewin SA, Liu E, Madenci A, Majkrzak AA, Peterson SF, Serecky KA, Wilkinson DA, Wojcik BM, Englesbe MJ, Lynch RJ. Resident workload, pager communications, and quality of care. World J Surg 2010; 34: 2524-2529.

12. Ortega GR, Taksali S, Smart R, Baumgaertner MR. Direct cellular vs. Indirect pager communication during orthopaedic surgical procedures: A prospective study. Technol Health Care 2009; 17: 149-157.

13. Fortney JC, Burgess JF, Bosworth HB, Booth BM, Kaboli PJ. A reconceptualization of access for 21st century healthcare. J Gen Intern Med 2011; 26: 639-647.

14. Greene AH. HIPAA Compliance for clinician texting. J AHIMA 2012; 83: 34-36.

15. Przybylo JA, Wang A, Loftus P, Evans KH, Chu I, Shieh L. Smarter hospital communication: Secure smartphone text messaging improves provider satisfaction and perception of efficacy, workflow. J Hosp Med 2014; 9: 573-578.

16. Wu R, Rossos P, Quan S, Reeves S, Lo V, Wong B, Cheung M, Morra D. An evaluation of the use of smartphones to communicate between clinicians: A mixed-methods study. J Med Internet Res 2011; 13: e59.

17. Vazirani S, Hays R, Shapiro M, Cowan M. Effect of a multidisciplinary intervention on communication and collaboration among physicians and nurses. Am J Crit Care 2005; 14: 71-77.

18. Baker DP, Day R, Salas E. Teamwork as an essential component of high-reliability organizations. Health Serv Res 2006; 41: 1576-1598.

19. Rivera AJ and Karsh BT. Interruptions and distractions in healthcare: review and reappraisal. Qual Saf Health Care 2010; 19: 304-312.

20. Wu RC, Lo V, Morra D, Wong BM, Sargeant R, Locke K, Cavalcanti R, Quan SD, Rossos P, Tran K, Cheung $\mathrm{M}$. The intended and unintended consequences of communication systems on general internal medicine inpatient care delivery: a prospective observational case study of five teaching hospitals. J Am Med Inform Assoc 2013; 20: 766-777.

21.Wu RC, Morra D, Quan S, Lai S, Zanjani S, Abrams H, Rossos PG. The use of smartphones for clinical communication on internal medicine wards. J Hosp Med 2010; 5: 553-559.

22. Khanna RR, Wachter RM, Blum M. Reimaging electronic clinical communication in the post-pager, smartphone era. JAMA 2016; 315(1): 22. 